\title{
Tilamallitarkastelu tulevan EU:n sokeripolitiikan uudistuksen vaikutuksista Suomessa
}

\author{
Ellen Huan-Niemi ${ }^{1}$, Petri Liesivaara ${ }^{1}$, Jukka Tauriainen ${ }^{1}$ ja Jeroen Buysse ${ }^{2}$ \\ ${ }^{1}$ MTT Taloustutkimus, Latokartanonkaari 9, 00790 Helsinki, etunimi.sukunimi@mtt \\ ${ }^{2}$ Ghent University, Coupure Links 653, B-9000 Gent, J.Buysse@ugent.be
}

\section{Tiivistelmä}

Sokerintuotanto on säilynyt Suomessa kansallisen sokerijuurikkaan tuen ja kiintiöjärjestelmän ansiosta. Komission näkemyksen mukaan kiintiöjärjestelmä rajoittaa EU:n sokerintuotantoa ja haittaa tuotannon kilpailukykyä maailmassa. Sokerikiintiöistä luopuminen mahdollistaisi tuotannon kasvattamisen niissä EU:n jäsenmaissa, jotka ovat kilpailukykyisimpiä EU:ssa.

EU:n komissio ehdotti maatalouspolitiikan uudistusesityksessä sokerikiintiöiden poistamista jo vuonna 2015. Tässä tutkimuksessa tarkastellaan sokerin hallinnollisen hinnan alentamisen, sokerikiintiöiden poiston, kansallisen sokerijuurikkaan tuen ja muiden viljelykasvien hinnan nousun vaikutusta sokerijuurikkaan viljelyyn Suomessa. Tutkimustulokset mallinnettiin positiivisella matemaattisella simulointimallilla. Aineistona tutkimuksessa ovat suomalaiset sokerijuurikasta viljelevät kirjanpitotilat.

Valkosokerin hallinnollisen hinnan alentaminen $20 \%$ (vastaa 23,4\% sokerijuurikkaan hinnan laskua) vähentäisi sokerijuurikkaan viljelyä tulosten mukaan keskimäärin noin $26 \%$ tutkimusaineistona olevilla tiloilla. Mikäli valkosokerin hallinnollista hintaa lasketaan $10 \%$ (vastaa $11,7 \%$ sokerijuurikkaan hinnan laskua), sokerijuurikkaan viljely vähentyisi mallin mukaan keskimäärin noin $13 \%$. Kiintiöiden poiston vaikutuksesta sokerijuurikkaan viljelyyn tehtiin herkkyysanalyysi, koska sokerikiintiöiden poiston vaikutusta valkosokerin ja sokerijuurikkaan hintaan EU:ssa on vaikea arvioida. Mikäli sokerijuurikkaan hinta laskee 10-50 \%, niin tuotanto vähenee 11-56 \% nykyisellä sokerijuurikkaan kansallisella tuella ja 40-85 \% ilman kansallista tukea. Mikäli kansallinen tuki poistetaan kokonaan eikä sokerijuurikkaan hinta muutu, sokerijuurikkaan viljely vähenee mallin mukaan $29 \%$.

Kansallisella tuella on hyvin tärkeä rooli sokerijuurikkaan tuotannon jatkumiselle Suomessa. Jos sokerijuurikkaan hinnan lasku halutaan kompensoida kansallisella sokerijuurikkaan tuella, $10 \%$ hinnan alennus vaatisi 489 euroa/ha, jotta nykyinen tuotannon taso säilytettäisiin. Tarvittava tukimäärä 20 $\%$ sokerijuurikkaan hinnan alennuksessa olisi 616 euroa/ha. Nykyisen tuotannon tason säilyttämiseksi sokerijuurikkaan hinnan tulisi nousta $26 \%$ ilman kansallista sokerijuurikkaan tukea. Ilman sokerikiintiöitä Säkylän tehtaan tulisi toimia täydellä kapasiteetilla ja sokerintuotantoa voisi mahdollisesti kasvattaa $20 \%$ nykyisestä, jolloin kansallisen tuen tulisi olla 593 euroa/ha. Ilman kansallista tukea sokerijuurikkaan hinnan tulisi nousta $44 \%$, jotta tuotanto kasvaisi $20 \%$. Sokerijuurikkaan viljelypäätöksiin vaikuttavat myös viljojen ja öljykasvien hintataso. Muiden viljelykasvien $30 \%$ hinnannousu vähentäisi sokerijuurikkaan viljelyä noin $10 \%$ ja $70 \%$ hinnannousu vähentäisi viljelyä noin $24 \%$. Ilman sokerijuurikkaan kansallista tukea, sokerijuurikkaan viljely laskisi jyrkemmin.

Sokerintuotannosta luopuminen aiheuttaisi seurauksia Suomen elintarvikeketjun omavaraisuudelle. Sokerijuurikkaan viljelyn jatkuminen Suomessa vaatii uusien ja vanhojen politiikkakeinojen käyttöä rinnakkain. Vuonna 2013 toteutettava yhteisen maatalouspolitiikan uudistus antaa mahdollisuuden ottaa uusia välineitä käyttöön sokerijuurikkaan viljelyn tukemiseksi ja kehittämiseksi. Sokerijuurikkaan satojen tulisi tulevaisuudessa kasvaa Suomessa suhteessa enemmän kuin muissa EU:n jäsenmaissa. Lisäksi kannustavan tuen rinnalla tarvitaan myös parempaa tuottajahintaa sokeriteollisuudelta, jotta sokerijuurikkaan tuotanto voisi jatkua Suomessa ilman sokerikiintiöitä.

\section{Avainsanat:}

EU:n sokeripolitiikka, tilamalli, sokerikiintiö, kansallistuki, viljelykasvien hinta, satotaso 


\section{Johdanto}

Sokerin markkinajärjestely on ollut EU:ssa käytössä jo vuodesta 1968 asti. Järjestelmän tarkoituksena on ollut taata viljelijöille riittävä tulotaso ja varmistaa omavaraisuus sokerintuotannossa. Markkinajärjestely on pitänyt sokerin sisämarkkinahinnan maailmanmarkkinahinnan yläpuolella tuontitullien ja vientitukien avulla. Tämä järjestelmä johti lopulta sokerin ylituotantoon unionissa. Ylimääräinen tuotanto oli vietävä vientituen avulla unionista. Tuontitulleista huolimatta EU on myöntänyt bilateraalisia ja yksipuolisia kauppamyönnytyksiä eräille kehitysmaille.

Vientituet ja sokerin korkeat hinnat EU:ssa olivat valitun politiikan kääntöpuolena. EU:n hintataso oli ennen vuotta 2006 kolme kertaa korkeampi kuin maailmanmarkkinoilla vallitseva markkinahinta. Tuotantoa oli vähennettävä EU:n kehittyville maille antamien kauppamyönnytysten myötä lisääntyneen tuonnin takia. Tuotannon vähentämisen tarpeeseen vaikutti myös maailmankauppajärjestön paneelin päätös vuonna 2005 koskien EU:n sokeripolitiikkaa ja sitä kautta vientimahdollisuuksien vähentyminen.

Sokeripolitiikan reformi vuonna 2006 vähensi EU:n sokerintuotantoa ja muutti EU:n sokerin nettoviejästä sokerin nettotuojaksi. Kulutus ja tuotanto ovat reformin jälkeen paremmin tasapainossa, eikä ylimääräisen sokerin vientiä jouduta enää tukemaan vientituilla. Tehdyillä toimilla EU:n sokerin vienti on vähentynyt noin 3 miljoonalla tonnilla. Toisaalta EU:n markkinat ovat tulleet entistä riippuvaisemmiksi tuodusta sokerista. EU:n sokerireformilla on ollut vaikutusta myös sokerin maailmanmarkkinoihin, koska maailmanmarkkinoilta EU:n merkitys sokerin viejänä on vähentynyt.

EU:n sokerintuotantoon kohdistuu edelleen uudistuspaineita (Liesivaara ym. 2011). EU:n sokerin markkinajärjestelmään saatetaan vaatia lisää muutoksia samalla, kun yhteistä maatalouspolitiikkaa uudistetaan vuonna 2013. Suomessa on jo suljettu yksi sokeritehdas aikaisempien reformien seurauksena. Maitokiintiöiden poistaminen vuonna 2015 asettaa paineita myös sokerikiintiöistä luopumiseen. Toisaalta tuotannosta luopuminen eräissä maissa on aiheuttanut vakavia vaikeuksia erityisesti markkinointivuoden 2010/2011 tilanteessa, jossa sokerintuotanto EU:ssa ei riitä vastaamaan sisämarkkinoiden kysyntää. Vuoden 2010 toisella puoliskolla kohonneet viljojen hinnat kannustavat monissa maissa viljelijöitä siirtämään tuotantoa sokerijuurikkaasta viljoihin.

Kiintiöiden poistaminen vaikuttaisi unionin sisämarkkinoilla olevaan sokerin hintaan. Sokerin hinnalla olisi vaikutusta myös sokerijuurikkaasta viljelijöille maksettavaan hintaan. Tässä tutkimuksessa tarkastellaan sokerin hallinnollisen hinnan alentamisen, sokerikiintiöiden poiston, kansallisen sokerijuurikkaan tuen ja muiden viljelykasvien hinnan nousun vaikutusta sokerijuurikkaan viljelyyn Suomessa. Tutkimustulokset mallinnettiin matemaattisen ohjelmoinnin tilamallilla. Analyysin aineistona käytetään suomalaisia sokerijuurikasta viljeleviä kirjanpitotiloja.

\section{Aineisto ja menetelmä}

Tämän tutkimuksen aineistona käytetään suomalaisten sokerijuurikasta viljelevien kirjanpito-tilojen tuotantotietoja (FADN-Farm Accountancy Data Network). Tutkimustulokset on simuloitu Ghentin yliopistossa yksittäisten tilojen positiivisella matemaattisella simulointimallilla. Koska mallissa osa parametreista sovitetaan havaittuun aineistoon sopivaksi, mallia kutsutaan positiiviseksi (Buysse ym. 2007).

Tutkimusaineisto koostuu 40 sokerijuurikasta viljelevästä FADN:n kirjanpitotilasta. Aineisto on vuodelta 2000-2008. Vuonna 2008 sokerijuurikasta viljeleviä kirjanpitotiloja oli enää 22. Taulukossa 1 on kuvattu vuoden 2008 aineiston jakautumista ja sen perustietoja.

Tutkimusaineistona olevilla tiloilla viljeltiin vuonna 2008 sokerijuurikasta keskimäärin 11,9 hehtaarin alalla. Tilojen pinta-ala oli keskimäärin 73,9 hehtaaria, joten sokerijuurikas muodosti noin $16 \%$ koko tilojen viljellystä pinta-alasta. Tilojen keskisato oli koko maan keskisatoa (34 $520 \mathrm{~kg} / \mathrm{ha})$ korkeampi eli noin $38000 \mathrm{~kg} / \mathrm{ha}$. 
Taulukko 1. Ote tutkimusaineistosta vuoden 2008 tiloista.

\begin{tabular}{|l|r|}
\hline & Aineisto \\
\hline Tilojen lukumäärä & 22 \\
\hline Sokerijuurikkaan viljelty ala yhteensä & 261,66 \\
\hline Sokerijuurikkaan viljelty ala keskimäärin & 11,9 \\
\hline Tilojen viljelty peltoala keskimäärin & 73,9 \\
\hline Sokerijuurikkaan osuus koko viljeltävästä alasta keskimäärin \% & 16,1 \\
\hline Keskimääräinen sokerijuurikkaan sato (kg/ha) & 38200 \\
\hline Keskimääräinen sokerijuurikkaan hinta (€/tonni) & $35,4^{*}$ \\
\hline
\end{tabular}

*Hinta sisältää tehtaan maksaman kuljetuskorvauksen ja korkeammasta sokeripitoisuudesta maksetun hinnankorotuksen.

\section{Tulokset}

\section{Hallinnollisten hintojen alentamisen vaikutukset sokerijuurikkaan viljelyyn}

Hallinnollinen viitehinta on se minimihinta, joka laukaisee sokerin yksityisen varastoinnin. Kuviossa 1 on kuvattu mallin tulokset, kun valkosokerin hallinnollista viitehintaa on laskettu 10 ja $20 \%$ poistamatta EU:n sokerikiintiötä. Valkosokerin viitehinnan alentaminen $10 \%$ merkitsisi 11,7 \% sokerijuurikkaan hallinnollisen hinnan alentamista. Sen sijaan $20 \%$ viitehinnan alennus valkosokerin hallinnollisessa hinnassa merkitsisi $23,4 \%$ hinnan alennusta sokerijuurikkaan hallinnollisessa viitehinnassa. Valkosokerin hinnan lasku on siirretty sokerijuurikkaan hintaan samassa suhteessa kuin niiden hintaa laskettiin vuoden 2006 sokeriuudistuksessa. Kuvion 1 vaaka-akselissa on tutkimusaineistona olevat 22 sokerijuurikasta viljelevää tilaa ja pystyakselissa muutos sokerijuurikkaan viljelyssä eri tiloilla.

Valkosokerin viitehinnan alentaminen $20 \%$ vähentäisi tulosten mukaan sokerijuurikkaan viljelyä keskimäärin noin $26 \%$ tutkimusaineistona olevilla tiloilla. Yhdellä tilalla sokerijuurikkaan viljely vähenisi peräti $32 \%$. Mikäli valkosokerin viitehintaa lasketaan $10 \%$, sokerijuurikkaan viljely vähentyisi mallin mukaan keskimäärin noin $13 \%$. Tulokset ovat hyvin samansuuntaiset eri tilojen välillä.

Sokerijuurikasta viljelevät tilat

$$
\begin{array}{llllllllllllllllllllll}
1 & 2 & 3 & 4 & 5 & 6 & 7 & 8 & 9 & 10 & 11 & 12 & 13 & 14 & 15 & 16 & 17 & 18 & 19 & 20 & 21 & 22
\end{array}
$$

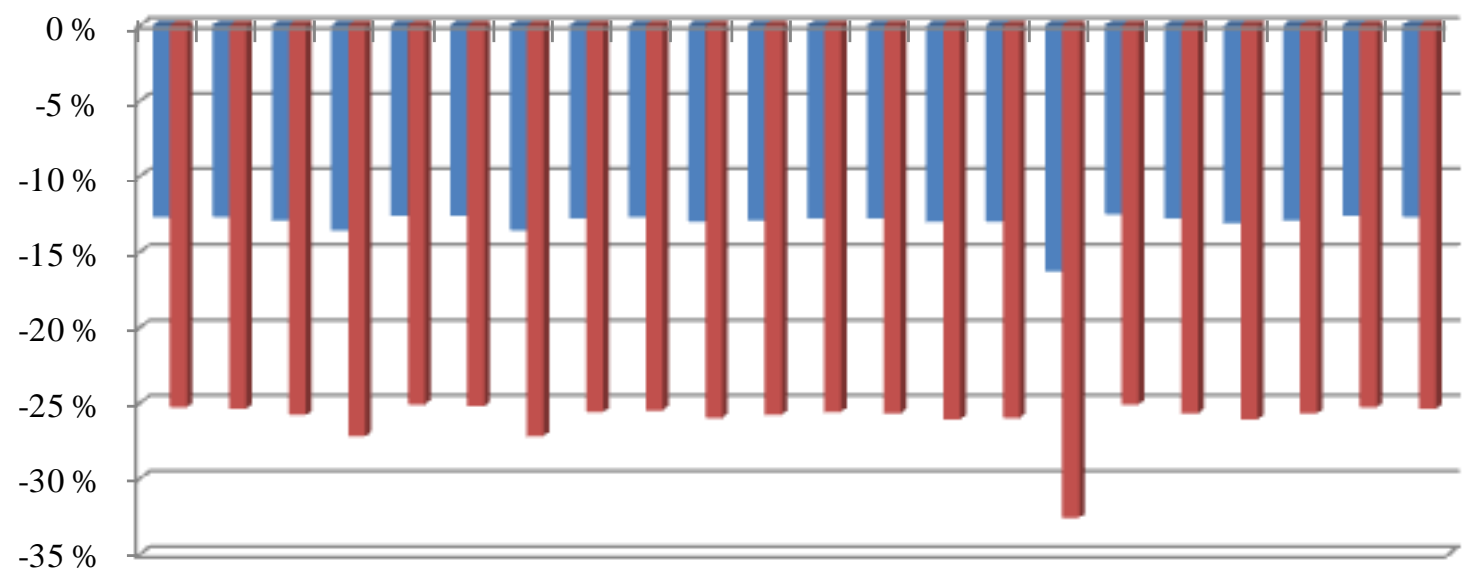

- Valkosokerin viitehinnan lasku $10 \%$, sokerijuurikkaan hallinnollisen hinnan lasku 11,7\%

- Valkosokerin viitehinnan lasku $20 \%$, sokerijuurikka an hallinnollisen hinnan lasku 23,4\%

Kuvio 1. Valkosokerin viitehinnan laskun vaikutukset sokerijuurikkaan viljelyyn. 


\section{Muiden viljelykasvien hintojen vaikutus sokerijuurikkaan tuotantoon}

Vilja- ja öljykasvien hinnoissa on koettu kaksi merkittävää hintapiikkiä vuoden 2006 jälkeen. Ensimmäinen koettiin vuonna 2007, jolloin viljojen markkinahinnat nousivat ennätyskorkealle. Hinnat kuitenkin laskivat lähes yhtä nopeasti kuin ne olivat nousseetkin. Vuoden 2010 heinäkuussa viljojen hinnat lähtivät jälleen nousuun. Vuoden 2011 alkupuolella ylitettiin jo vuosien 2007/2008 ennätyskorkea hintataso. Viljojen ja öljykasvien hinnoilla on luonnollisesti myös vaikutusta viljelijöiden tekemiin sokerijuurikkaan viljelypäätöksiin.

Käytettävällä mallilla voidaan simuloida viljelykasvien hintojen vaihtelun vaikutusta sokerijuurikkaan viljelyyn. Suomessa sokerijuurikkaalle vaihtoehtona ovat vilja- tai öljykasvit, kun esimerkiksi Keski-Euroopassa sokerijuurikasta voivat käyttää myös etanolia tuottavat laitokset. Viljojen ja öljykasvien vaikutusta sokerijuurikkaan viljelyyn mallinnettiin nostamalla niiden markkinahintaa 30 ja 70 $\%$ vuoden 2008 hintatasosta. Kilpailevien kasvien vaikutus sokerijuurikkaan viljelyyn on esitetty kuviossa 2.

Mikäli viljojen ja öljykasvien hinnat nousevat vuoden 2008 tasosta $30 \%$, sokerijuurikkaan viljely laskee $10 \%$. Tällöin kasvaa erityisesti rukiin, vehnän ja öljykasvien viljely tutkimusaineistona olevilla tiloilla (Kuvio 2). Sen sijaan jos hinnat nousevat $70 \%$, sokerijuurikkaan viljely vähenisi $24 \%$.

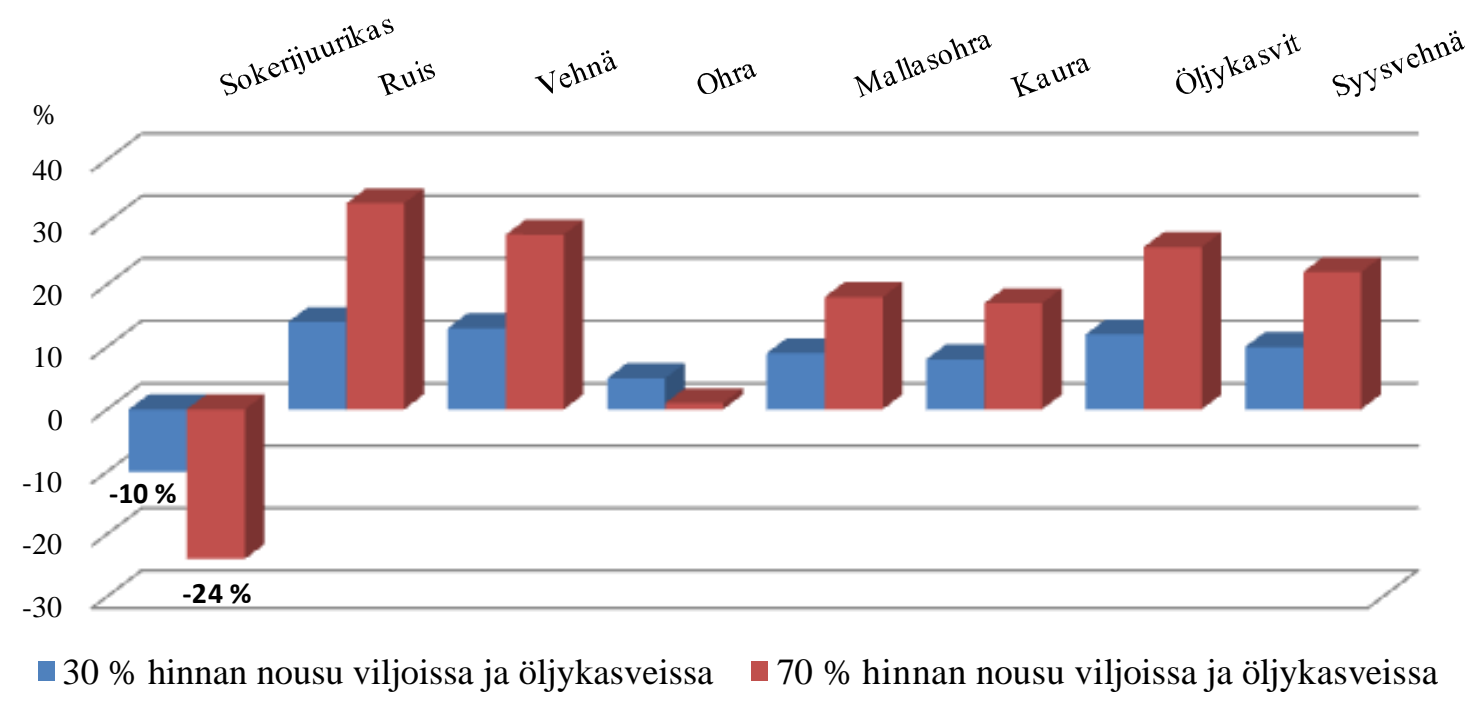

Kuvio 2. Viljojen ja öljykasvien hinnan nousun vaikutus sokerijuurikkaan viljelyyn Suomessa.

\section{Sokerikiintiöiden poiston ja kansallisen tuotantoon sidotun tuen vaikutus sokerijuurikkaan vilje- lyyn Suomessa}

Kiintiöiden poistamisen vaikutusta juurikkaasta maksettavaan hintaan on vaikea mallintaa. Ensinnäkin on hankala selvittää miten kiintiöiden poisto vaikuttaisi eri EU:n jäsenmaissa. Lisäksi on vaikea arvioida, miten valkosokerin hinnan muutokset heijastuisivat sokerijuurikkaan hintaan eri jäsenmaissa. Sokerikiintiöjärjestelmä on ollut voimassa yli 40 vuotta eli EU:ssa ei ole kokemuksia ilman kiintiöitä toimivista sokerimarkkinoista.

Koska kiintiöiden poiston vaikutusta sokerijuurikkaan hintoihin on erittäin vaikea arvioida, kuviossa 3 on tarkasteltu sokerijuurikkaan hinnan muuttumisen vaikutusta sokerijuurikkaan viljelyyn Suomessa aina $50 \%$ hinnan laskuun asti. Tarkastelun lähtökohtana on siis oletus, että sokerijuurikkaasta maksettava hinta laskee, mikäli sokerikiintiöt poistetaan. Lisäksi kuviossa 3 on kuvattu kansallisen tuotantoon sidotun tuen vaikutusta sokerijuurikkaan tuotantoon.

Mallin mukaan $10 \%$ alennus sokerijuurikkaan hinnassa vähentäisi sokerijuurikkaan viljelyä noin $11 \%$ (Kuvio 3). Sen sijaan jos hinta laskee 20-50\%, niin sokerijuurikkaan tuotanto laskee 22-56 $\%$. 


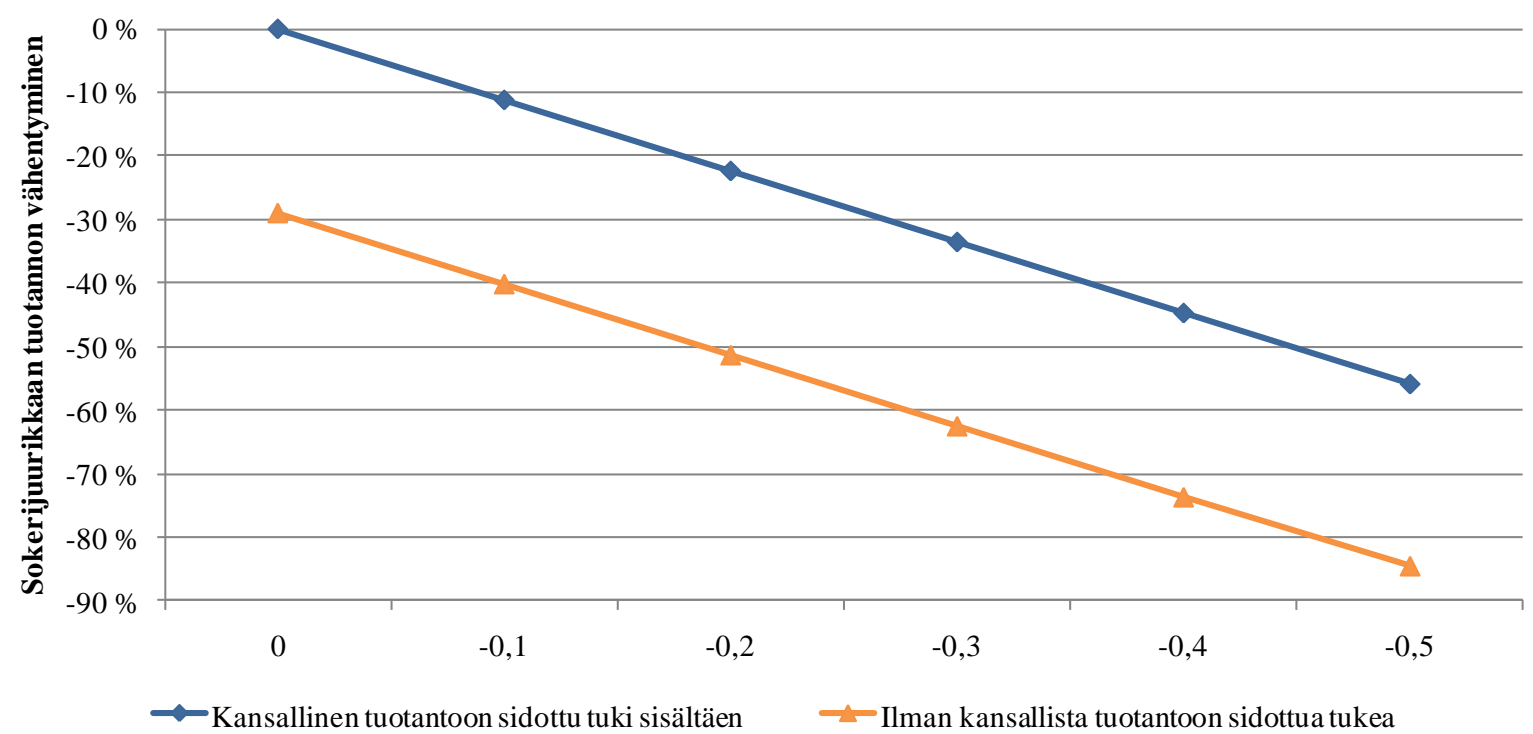

Kuvio 3. Hinnan alennuksen vaikutus sokerijuurikkaan tuotantoon Suomessa sekä kansallisen tuotantoon sidotun tuen merkitys tuotantoon.

Kuviossa 3 on esitetty myös tuotantoon sidotun kansallisten tuen poistamisen vaikutus sokerijuurikkaan viljelyyn Suomessa. Kansallisen tuen määrä on 350 euroa hehtaarilta. Mikäli kansallinen tuki poistetaan kokonaan eikä sokerijuurikkaasta maksettu hinta muutu, sokerijuurikkaan viljely vähenee mallin mukaan $29 \%$ (Kuvio 3). Mikäli tuotantoon sidotun kansallisen tuen poistamisen lisäksi sokerijuurikkaan hinta laskee 10-50\%, sokerijuurikkaan viljely vähenee mallin mukaan 40-85\% (Kuvio 3).

Taulukossa 2 on mallin tulokset sokerijuurikkaan kansallisen tuen ja sokerijuurikkaan hinnan vaikutuksesta sokerijuurikkaan viljelyyn. Keskimmäisessä sarakkeessa on tarvittava kansallisen tuen määrä, jotta tuotannon nykyinen taso säilytetään. Tämä tarkoittaa valkosokerin tuotantomäärässä 69 000-87 500 tonnia. Määrä vastaa sokerijuurikkaan sadon vaihtelua vuosina 2008-2010. Oikeanpuolimaisessa sarakkeessa on tarvittava kansallisen tuen taso, jotta tuotannon taso kasvaisi $20 \%$. Näin vuosittainen valkosokerin tuotantomäärä olisi noin 83 400-105 000 tonnia. Vasemmanpuoleisessa sarakkeessa on sokerijuurikkaasta maksettavan hinnan taso.

Taulukko 2. Sokerijuurikkaan kansallisen tuen tarve vaihtoehtoisilla sokerijuurikkaan hinnoilla.

\begin{tabular}{|c|c|c|}
\hline \multirow{2}{*}{} & \multicolumn{2}{|c|}{ Kansallinen sokerijuurikkaan tuki $€ /$ ha } \\
\cline { 2 - 3 } & Tuotannon taso (nykyinen) & Tuotannon taso (+20 \%) \\
\hline Sokerijuurikkaan hinta & $69500-87500 \mathrm{t}$ (valkosokeri) & $83400-105000 \mathrm{t}$ (valkosokeri) \\
\hline & $470000-560000 \mathrm{t}$ (sokerijuurikas) & $564000-672000 \mathrm{t}$ (sokerijuurikas) \\
\hline & & 593 \\
nykyinen taso & 350 & 728 \\
$-10 \%$ & 489 & 861 \\
$-20 \%$ & 616 & 0 \\
$+44 \%$ & - & - \\
$+26 \%$ & 0 & 350 \\
\hline$+18 \%$ & - & \\
\hline
\end{tabular}

Jos sokerijuurikkaan hinta laskee $10 \%$, kansallisen sokerijuurikkaan tuen tulisi mallin mukaan olla 489 euroa/ha, jotta nykyinen tuotannon taso voitaisiin säilyttää. Jos sokerijuurikkaan hinta laskee $20 \%$, kansallisen tuen tulisi olla 616 euroa/ha nykyisen tuotannon tason säilyttämiseksi. Sen sijaan ilman kansallista sokerijuurikkaan tukea, sokerijuurikkaasta maksettavan hinnan tulisi nousta $26 \%$, mikäli nykyinen tuotannon taso halutaan säilyttää (Taulukko 2). 
Jos tuotantoa halutaan kasvattaa $20 \%$ nykyisestä, kansallisen tuen tulisi mallin mukaan olla 593 euroa/ha nykyisellä hintatasolla. Mikäli sokerijuurikkaasta maksettava hinta laskee $10 \%$ nykyisestä, $20 \%$ korkeamman tuotannon tason saavuttaminen vaatisi 728 euroa/ha kansallista tukea. Hinnan aleneminen $20 \%$ vaatisi 861 euroa/ha kansallista tukea, jos sokerijuurikkaan tuotannon halutaan nousevan $20 \%$. Nykyisellä kansallisella tuella $20 \%$ korkeampi tuotanto saavutetaan $18 \%$ korkeammalla sokerijuurikkaan hinnalla. Sen sijaan ilman sokerijuurikkaan kansallista tukea hinnan tulisi olla $44 \%$ nykyistä korkeampi, jotta tuotanto kasvaisi $20 \%$ (Taulukko 2).

\section{Johtopäätökset}

Sokerikiintiöiden poiston vaikutusta sokerijuurikkaan hintoihin on vaikea arvioida. Mikäli juurikassokerin tuotanto halutaan säilyttää Suomessa, on tärkeää ettei sokerijuurikkaan hinta laske nykyisestä tasosta. On kuitenkin mahdollista, että sokerikiintiöiden poistaminen laskee sokerijuurikkaan hintaa. Sokerin hinnan lasku vaikuttaa välittömästi sokerijuurikkaan tuotettuun määrään Suomessa. Valkosokerin hinnan alentaminen $20 \%$ vähentäisi sokerijuurikkaan viljelyä tulosten mukaan keskimäärin noin $26 \%$ tutkimusaineistona olevilla tiloilla. Mikäli valkosokerin hintaa lasketaan $10 \%$, sokerijuurikkaan viljely vähentyisi mallin mukaan keskimäärin noin $13 \%$. Tämä tarkoittaisi sitä, että Suomen ainoa sokerijuurikasta jalostava tehdas Säkylässä ei voisi jatkaa sokerintuotantoa. Jo tällä hetkellä tehtaan käyttökapasiteetti on melko alhaalla. Tehtaan käyntikausi oli vuonna 2010 vain 77 päivää, joka on yksi alhaisimmista EU:ssa. Vuonna 2010 sokerijuurikasta jalostavien tehtaiden käyntipäivien määrä oli EU-25:ssä keskimäärin 123 päivää (CEFS 2010). Jos raaka-aineen toimitettu määrä tehtaalle laskee edes $13 \%$, tehtaan tuotannon jatkaminen ei ole kannattavaa pitkällä aikavälillä.

Suomen luonnonolosuhteista johtuvaa matalaa satotasoa ja sen aiheuttamia korkeita sokerijuurikkaan tuotannon kustannuksia korvataan kansallisella sokerijuurikkaan tuella. Keski-Euroopan maiden sokerijuurikkaan viljelyn matalat kustannukset (€/tonni) Suomeen verrattuna johtuvat alueen korkeammista hehtaarisadoista. Korkeasta sadosta johtuen Keski-Euroopan maita pidetään viljelyolosuhteiltaan kilpailukykyisimpinä EU:ssa. Satotason nostaminen on yksi edellytys sokerijuurikkaan viljelyn jatkumiselle Suomessa, mikäli sokerikiintiöjärjestelmästä luovutaan. Kannustavan tuen rinnalla tarvitaan myös parempaa tuottajahintaa sokeriteollisuudelta, jotta sokerijuurikkaan tuotanto voisi jatkua Suomessa ilman sokerikiintiöitä.

EU:n viljelyolosuhteiltaan edullisimmilla alueilla sokerijuurikasta pystytään tuottamaan alle EU:n nykyisen sokerijuurikkaan minimihinnan, ja mikäli sokerijuurikkaasta maksettava hinta laskee kiintiöiden poiston seurauksena, tuotanto todennäköisesti keskittyy näille viljelyolosuhteiltaan suotuisimmille alueille. Tuotannon keskittyminen aiheuttaisi merkittäviä taloudellisia, sosiaalisia ja ympäristöllisiä seurauksia. Myös Euroopan komission (2011) mukaan maataloustuotannon keskittyminen vain tietyille alueille aiheuttaa merkittäviä negatiivisia vaikutuksia. Alueet, joille tuotanto keskittyisi, kärsisivät lisääntyneestä tuotannon tehostamisesta. Tuotannon tehostaminen aiheuttaisi lisäpainetta luonnonvarojen, kuten maatalousmaan ja vesistöjen käytölle. Vastaavasti vähemmän kilpailukykyiset alueet kärsisivät negatiivisista seurauksista niiden taloudellisessa ja sosiaalisessa rakenteessa.

\section{Kirjallisuus}

Buysse, J., Fernagut, B., Harmignie, O., de Frahan, B. H., Lauwers, L., Polomé, P., Van Huylenbroeck, G. \& Van Meensel, J. 2007. Farm-based modelling of the EU sugar reform: impact on Belgian sugar beet suppliers. European Review of Agricultural Economics 34(1): 21-52

CEFS 2010. CEFS Sugar Statistics 2010. Comite Europeen des Fabricants de Sucre. Brussels. Saatavissa internetissä:http://www.comitesucre.org/userfiles/file/Statistics/CEFS\%20Sugar\%

20Statisitics\%20Inquiry\%202202\%20-FINALDECEMBER2010.doc Viitattu: 20.5.2011

Euroopan komissio 2011. The CAP in pespective: from market intervention to policy innovation. Agricultural Policy Perspectives Briefs. Brief No 1. January 2011. Saatavissa internetissä: http://ec.europa.eu/agriculture/publi/app-briefs/01_en.pdf Viitattu: 18.5.2011

Liesivaara, P., Huan-Niemi, E., Taurianinen, J., \& Buysse, J. 2011. Suomen sokerituotannon tulevaisuus EU:n sokeripolitiikassa. MTT Raportti 26. 37 s. 